\title{
Risk Factors for Postpartum Maternal Infection Following Spontaneous Vaginal Delivery Complicated by Chorioamnionitis
}

\author{
Helen A. Daifotis, BA ${ }^{10}$ Megan M. Smith, BA ${ }^{1}$ Anna E. Denoble, MD, MSCR ${ }^{2}$ \\ Sarah K. Dotters-Katz, MD, MMHPE² \\ ${ }^{1}$ Duke University School of Medicine, Durham, North Carolina \\ 2 Department of Obstetrics and Gynecology, Duke University Medical \\ Center, Durham, North Carolina \\ Address for correspondence Helen Daifotis, BA, Duke University \\ School of Medicine, DUMC 3967, Durham, NC 27710 \\ (e-mail: helen.daifotis@duke.edu).
}

Am J Perinatol Rep 2020;10:e159-e164.

Abstract

Keywords
- chorioamnionitis
- intrapartum
antibiotics
- postpartum
antibiotics
- maternal morbidity
- postpartum infection
- preterm delivery
- spontaneous vaginal
delivery

Objective Guidelines for the management of chorioamnionitis include intrapartum antibiotics, while postpartum antibiotics after spontaneous vaginal delivery (SVD) are reserved high-risk women. Our objective is to describe the incidence of and risk factors for postpartum infection after SVD complicated by chorioamnionitis.

Study Design This is a retrospective study of SVDs with clinically diagnosed chorioamnionitis at a single center. The primary outcome was a composite of postpartum infection. Women who developed the primary outcome were compared with those who did not using bivariate statistics. Regression models were developed to estimate adjusted odds of outcomes.

Results In this cohort, 346 women underwent SVD complicated by chorioamnionitis. Of these, 23 (6.6\%) developed postpartum infections (endometritis $n=7$, urinary tract infection/pyelonephritis $n=6$, sepsis $n=4$, and perineal wound infection $n=6$ ). Receipt of antibiotics intra- or postpartum did not differ between groups, but women with postpartum infections were more likely to deliver prior to 32 weeks ( 17.4 vs. $4.9 \%$, $p=0.04)$. When controlling for antibiotic use, delivery at $<32$ weeks was associated with 3.8-fold increased (95\% confidence interval: 1.07-13.7) odds of postpartum infection.

Conclusion Postpartum infections occur in $\sim 1 / 15$ women delivering vaginally with chorioamnionitis, with those who deliver at $<32$ weeks' gestation being at increased risk.
Chorioamnionitis occurs when a bacterial infection leads to inflammation of the membranes and chorion of the placenta. The condition is not uncommon, occurring in 1 to $4 \%$ of term births and up to 5 to $10 \%$ of preterm births. ${ }^{1,2}$ In addition to preterm birth, other potential risk factors for developing chorioamnionitis are thought to include: prolonged rupture of membranes, internal labor monitoring, nulliparity, meconium-stained amniotic fluid, smoking, alcohol or drug abuse, immunocompromised status, colonization with group B Streptococcus, bacterial vaginosis, and sexually transmitted infections (STIs) during pregnancy. ${ }^{3}$

Timely and efficient identification and management of chorioamnionitis are important to minimize the risk of potential neonatal and maternal complications. A major concern for mothers affected by chorioamnionitis is the development of postpartum infections, such as wound infection, endometritis, sepsis, and bacteremia, which are three to four times more common in these women. ${ }^{3}$ In addition to received

September 8, 2019 accepted after revision March 5, 2020
DOI https://doi.org/

10.1055/s-0040-1709983. ISSN 2157-6998.
Copyright $\odot 2020$ by Thieme Medical Publishers, Inc., 333 Seventh Avenue, New York, NY 10001, USA. Tel: +1(212) 760-0888.
License terms

() (1) $\Theta \circledast$ 
infectious complications, these women are also at an increased risk of requiring a cesarean section and postpartum hemorrhage following either vaginal or cesarean delivery. ${ }^{3-5}$

In spite of the known complications and previous research in this area, there remains disagreement regarding the appropriate antibiotic regimen, and current practices are based largely on clinical consensus rather than large well-designed clinical trials. $^{3}$ Although existing evidence does support the use of intrapartum antibiotics, the role of postpartum antibiotics in preventing maternal postpartum infection is uncertain. Practices range from no treatment at all to 48 hours of postpartum antibiotics. ${ }^{6,7}$ Much of the existing literature on postpartum infection following chorioamnionitis has focused on cases that occur following cesarean delivery, where rates of postpartum infections are notably higher, ${ }^{8}$ whereas literature describing the incidence of infections or providing guidance with regard to the appropriate antibiotic management after vaginal delivery complicated by chorioamnionitis is more limited. Though large randomized controlled trials have been attempted, the conclusions have not been robust due to low enrollment and low rates of the primary outcome. ${ }^{9,10}$ The current committee opinion released by the American College of Obstetricians and Gynecologists (ACOG) states that women with chorioamnionitis who undergo spontaneous vaginal delivery (SVD) may not require antibiotics postpartum. ${ }^{11}$ However, this recommendation is supported by a study where the reduced treatment arm did, in fact, receive a dose of antibiotics postpartum. ${ }^{12}$ Given the clinical equipoise that exists, the objective of this study is to investigate the incidence of postpartum infections in women with clinical chorioamnionitis following SVD, and, if possible, identify risk factors associated with this outcome.

\section{Materials and Methods}

The study was reviewed and approved by the Institutional Review Board at Duke University (IRB: Pro00089967). Women in this study were identified using discharge International Classification of Diseases, 9th Revision and International Classification of Diseases, 10th Revision codes to screen for vaginal delivery and chorioamnionitis between January 1, 2014, and December 21, 2017, at a single academic medical center. Women were included in the study if they delivered a nonanomalous fetus or fetuses, were clinically diagnosed with chorioamnionitis, and delivered vaginally. Women with delivery at less than 20 weeks, intrauterine fetal demise at any gestational age, and those missing delivery data were excluded. During the study period, at our institution, clinical chorioamnionitis was defined as fever $>38.0^{\circ} \mathrm{C}$ in addition to one or more of the following: maternal tachycardia, fetal tachycardia, fundal tenderness, and foul-smelling amniotic fluid. Women who were coded as having chorioamnionitis, but did not meet diagnostic criteria upon chart review were also excluded. From participants who met the diagnostic criteria, demographic data, chronic medical conditions, antepartum complications, delivery information, and postpartum complications and course were collected from the electronic medical record and stored in a REDCap database.
The primary outcome for this study was the incidence of postpartum infection within 6 weeks of a vaginal delivery complicated by chorioamnionitis. Postpartum infections included endometritis, perineal wound infection, sepsis, urinary tract infection (UTI), and pyelonephritis. Sepsis was defined by the systemic inflammatory response syndrome criteria in patients with a known source of infection (i.e., placenta or positive blood cultures) in addition to two or more of the following attributes: temperature $>38^{\circ} \mathrm{C}$ or $<36^{\circ} \mathrm{C}$, heart rate $>90$ beats per minute, respiratory rate $>20$ per minute or $\mathrm{PaCO}_{2}<32 \mathrm{~mm} \mathrm{Hg}$, and white blood cell $>12,000 / \mathrm{mm}^{3},<4,000 / \mathrm{mm}^{3}$, or $>10 \%$ bands. ${ }^{13}$ Endometritis was defined as fundal tenderness accompanied by fevers in the postpartum period. Wound infection was diagnosed based on clinical presentation with the appropriate combination of signs and symptoms. UTI and pyelonephritis were both included based on laboratory results and assessed with urinalysis and positive urine culture obtained prior to the initiation of antibiotics. The incidence of the individual components of the composite was also estimated. The incidence of other indicators of maternal morbidity including: development of fever of unknown origin, need for postpartum blood transfusion, need for manual placenta extraction, and need for postpartum dilation and curettage was also examined. Secondarily, we aimed to identify risk factors for development of postpartum infection. Antibiotics, both intrapartum and postpartum were given at the discretion of the obstetric provider. Intrapartum antibiotics included any antibiotics given during labor and prior to delivery, specifically for the indication of presumed chorioamnionitis. Postpartum antibiotics were defined as those given immediately postpartum and documented as prophylactic. If antibiotics were stopped and then restarted due to concern of infection, this was not included as receipt of postpartum antibiotics.

Women who experienced postpartum infections were compared with women who did not develop postpartum infections using bivariate statistics as appropriate. Multivariable logistic regression was used to estimate the adjusted odds of the primary outcome. The chosen variables were those that either demonstrated statistical significance in the preceding bivariate analysis and/or had biologic plausibility. Data analysis was performed using Stata software (version 14; Stata Corporation, College Station, TX). A $p$-value of $<0.05$ was considered statistically significant.

\section{Results}

Out of 346 women who met the criteria for inclusion in this study, 23 patients (6.6\%) experienced a postpartum infection (-Fig. 1). Endometritis occurred most commonly (2.0\%), though six women $(1.7 \%)$ had urinary pathology and an additional six (1.7\%) had a perineal infection. Noninfectious postpartum maternal morbidity was more common, with 14 (4.1\%) women readmitted, 14 (4.1\%) requiring a blood transfusion, and 19 (5.5\%) requiring manual placenta extraction ( - Table 1). The median length of stay postpartum was 2 days in both groups (interquartile range: 2,$2 ; p=0.72$ ). 


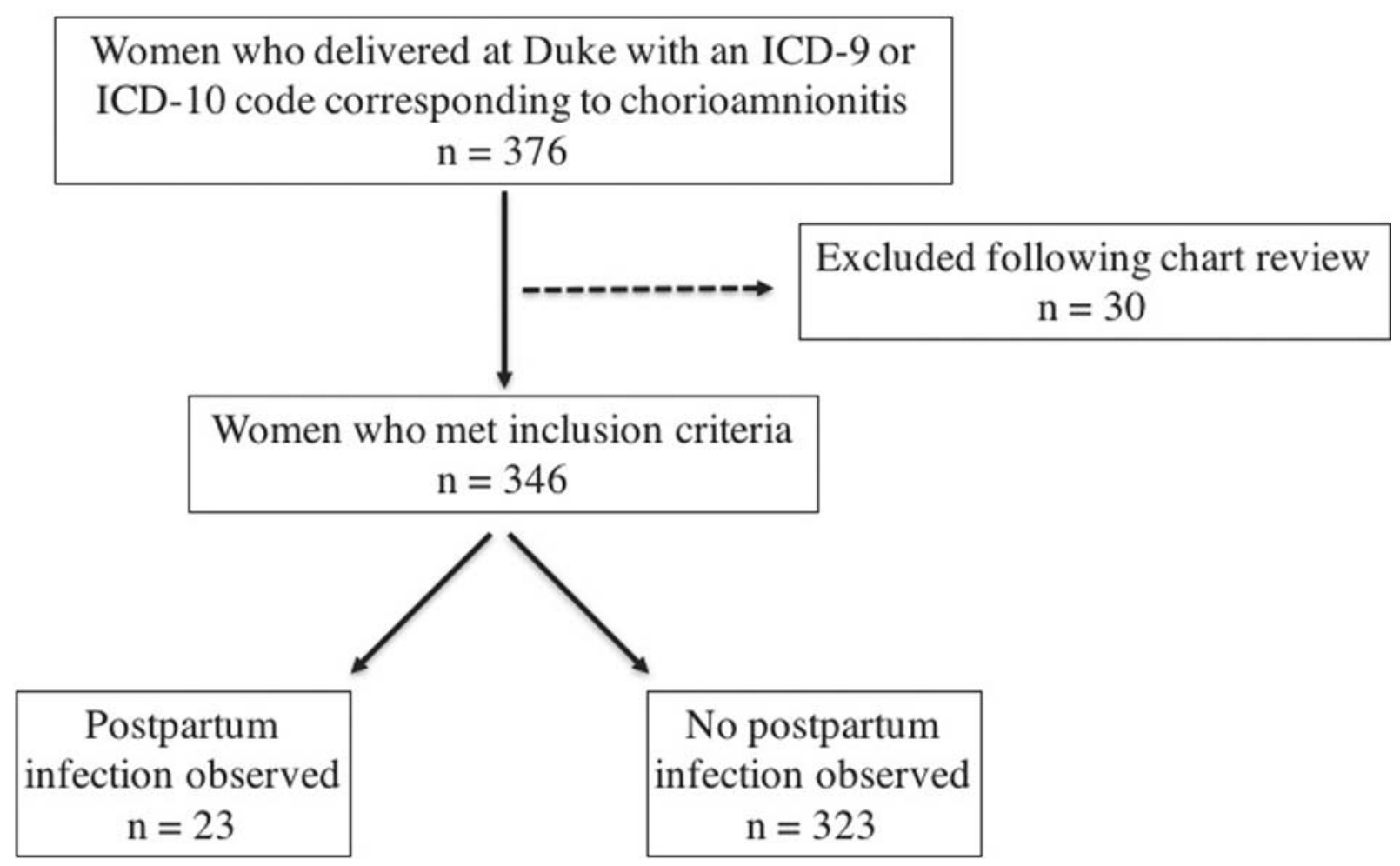

Fig. 1 Derivation of study cohort. ICD, International Classification of Diseases.

Table 1 Maternal morbidity after vaginal delivery complicated by chorioamnionitis

\begin{tabular}{|l|l|}
\hline & $\begin{array}{l}\text { Number of women affected } \\
n=346(\%)\end{array}$ \\
\hline Any postpartum infection & $23(6.6)$ \\
\hline Sepsis & $4(1.2)$ \\
\hline Endometritis & $7(2.0)$ \\
\hline UTI/pyelonephritis & $6(1.7)$ \\
\hline Perineal wound infection & $6(1.7)$ \\
\hline Fever of unknown origin & $2(0.6)$ \\
\hline Readmission & $14(4.1)$ \\
\hline Blood transfusion & $14(4.1)$ \\
\hline Manual placenta extraction & $19(5.5)$ \\
\hline Dilation and curettage & $11(3.2)$ \\
\hline
\end{tabular}

Abbreviation: UTI, urinary tract infection.

Women with postpartum infections were similar with respect to demographic composition to those who did not experience postpartum infections (-Table 2 ). The groups also demonstrated similar rates of chronic hypertension, asthma, preexisting diabetes mellitus, and STIs during pregnancy. In terms of antepartum complications, the groups did not demonstrate significant differences with respect to rates of preterm prelabor rupture of the membranes, intrauterine growth restriction, cerclage, gestational diabetes mellitus, preeclampsia, or group B Streptococcus colonization (-Table 3).

While the two groups were similar with respect to median gestational age at delivery (39.3 vs. 39.6 weeks), women in the group with postpartum infections were more likely to have delivered prior to 32 weeks ( 17.4 vs. $5 \%, p=0.04$ ) (-Table 4 ). Delivery at less than 37 and less than 34 weeks did not differ (data not shown). Intrapartum antibiotics were given to $60.9 \%$ of women who ultimately experienced postpartum infections and $73.1 \%$ of women who did not $(p=0.23)$. There was no difference in the number of doses of antepartum antibiotics received between the two groups (-Table 4). No differences in operative delivery, third or fourth degree lacerations, or manual placenta extraction were seen between the groups ( - Table 4). Postpartum antibiotics were given to $52.2 \%$ of women who ultimately experienced a postpartum infection and $30.7 \%$ of women who did not $(p=0.03)$. In regression models, delivery prior to 32 weeks was associated with a 3 8-fold increased odds of postpartum infection (95\% confidence interval [CI]: 1.07-13.7), while receipt of intrapartum antibiotics (adjusted odds ratio [aOR]: 0.43, 95\% CI: 0.17-1.10) and receipt of postpartum antibiotics (aOR: 2.25, 95\% CI: 0.91-5.58) were not found to be significant (-Table 5).

\section{Discussion}

The most recent ACOG Committee Opinion and the preponderance of data suggest that antibiotics may not be necessary after vaginal delivery. ${ }^{11,14,15}$ While not all women develop infectious complications following chorioamnionitis, previous research has established an intrapartum diagnosis of chorioamnionitis as a risk factor for the development of postpartum infections. ${ }^{4,8,15}$ A secondary analysis of data from the Consortium on Safe Labor (2002-2008) found 
Table 2 Maternal demographics among women with and without postpartum infectious complications

\begin{tabular}{|c|c|c|c|}
\hline & $\begin{array}{l}\text { With } \\
\text { postpartum } \\
\text { infection } \\
n=23(\%)\end{array}$ & $\begin{array}{l}\text { Without } \\
\text { postpartum } \\
\text { infection } \\
n=323(\%)\end{array}$ & $p$-Value \\
\hline $\begin{array}{l}\text { Median maternal } \\
\text { age in y (IQR) }\end{array}$ & $28(23,31)$ & $27(23,32)$ & 0.94 \\
\hline \multicolumn{4}{|l|}{ Race $(n=334)$} \\
\hline White & $9(39.1)$ & $98(30.3)$ & \multirow[t]{4}{*}{0.42} \\
\hline Black & $7(30.4)$ & $104(32.2)$ & \\
\hline Asian & $4(17.4)$ & 32 (9.9) & \\
\hline Other & $3(13.0)$ & $77(23.8)$ & \\
\hline Private insurance & $16(69.6)$ & $172(53.3)$ & 0.19 \\
\hline Multiples & $2(8.7)$ & $6(1.9)$ & 0.09 \\
\hline Multiparous & $5(21.7)$ & $66(20.4)$ & $>0.99$ \\
\hline $\begin{array}{l}\text { Chronic } \\
\text { hypertension }\end{array}$ & $1(4.3)$ & $11(3.4)$ & 0.57 \\
\hline History of asthma & $4(17.4)$ & $30(9.3)$ & 0.26 \\
\hline $\begin{array}{l}\text { Preexisting } \\
\text { diabetes mellitus }\end{array}$ & 0 & $6(1.9)$ & $>0.99$ \\
\hline $\begin{array}{l}\text { STI during } \\
\text { pregnancy }\end{array}$ & $2(8.7)$ & $33(10.2)$ & $>0.99$ \\
\hline Tobacco use & $1(4.3)$ & $22(6.8)$ & $>0.99$ \\
\hline THC use & 0 & $7(2.2)$ & $>0.99$ \\
\hline $\mathrm{BMI}>40$ & $4(17.4)$ & $49(15.2)$ & 0.77 \\
\hline $\mathrm{BMI}>50$ & $2(8.7)$ & $14(4.3)$ & 0.28 \\
\hline
\end{tabular}

Abbreviations: BMI, body mass index; IQR, interquartile range; STI, sexually transmitted infection; THC, tetrahydrocannabinol.

that 11.9 and $4.1 \%$ of women whose labor was affected by chorioamnionitis and delivered via cesarean section or vaginally, respectively, experienced adverse maternal outcomes including hysterectomy, postpartum transfusion, venous thromboembolism, endometritis, wound infection, intensive care unit admission, and death. ${ }^{15}$ When chorioamnionitis was not diagnosed, $2.9 \%$ of women who delivered vaginally and $4.2 \%$ of women who delivered via cesarean section experienced these complications. ${ }^{15}$ In the Safe Labor study group, the increased incidence of adverse maternal outcomes was found to be significant in the setting of cesarean delivery but not vaginal delivery. ${ }^{15}$ However, when individual outcomes were examined instead of the composite measure, there was a statistically significant increase in the frequency of developing endometritis ( 2 vs. $22 \%$ ) or perineal wound infection ( 2 vs. $33 \%$ ) in women who delivered vaginally without chorioamnionitis versus with chorioamnionitis. ${ }^{15}$ The findings from our population present a similar picture, with $6.6 \%$ of women who had a vaginal delivery complicated by chorioamnionitis developing a postpartum infection, of which $30 \%$ was endometritis and $26 \%$ perineal wound infection.

At present, antibiotic usage following vaginal delivery complicated by chorioamnionitis ranges from no additional
Table 3 Antepartum complications

\begin{tabular}{|l|l|l|l|}
\hline & $\begin{array}{l}\text { With } \\
\text { postpartum } \\
\text { infection } \\
\boldsymbol{n}=\mathbf{2 3}(\%)\end{array}$ & $\begin{array}{l}\text { Without } \\
\text { postpartum } \\
\text { infection } \\
\boldsymbol{n}=323 \text { (\%) }\end{array}$ & $p$-Value \\
\hline IUFD & 0 & 0 & - \\
\hline PPROM & $3(13)$ & $20(6.2)$ & 0.19 \\
\hline IUGR & 0 & $9(2.8)$ & $>0.99$ \\
\hline Cerclage & 0 & $8(2.5)$ & $>0.99$ \\
\hline $\begin{array}{l}\text { Gestational } \\
\text { diabetes } \\
\text { mellitus }\end{array}$ & $1(4.3)$ & $24(7.4)$ & $>0.99$ \\
\hline $\begin{array}{l}\text { Gestational } \\
\text { hypertension }\end{array}$ & $1(4.3)$ & $21(6.5)$ & $>0.99$ \\
\hline Preeclampsia & $2(8.7)$ & $16(5)$ & 0.34 \\
\hline $\begin{array}{l}\text { Severe } \\
\text { preeclampsia }\end{array}$ & 0 & $3(0.9)$ & $>0.99$ \\
\hline Group B Strep + & $4(17.4)$ & $75(23.2)$ & 0.79 \\
\hline $\begin{array}{l}\text { Median BMI at } \\
\text { delivery (IQR) }\end{array}$ & $28.6(25.4$, & $\begin{array}{l}31.1(27.4, \\
36.1)\end{array}$ & 0.15 \\
\hline
\end{tabular}

Abbreviations: BMI, body mass index; IQR, interquartile range; IUFD, intrauterine fetal demise; IUGR, intrauterine growth restriction; PPROM, preterm premature rupture of the membranes; Strep, Streptococcus.

postpartum antibiotics ( $\sim 34.6 \%$ of providers) to continuation of antibiotics for 48 hours postpartum ( $24.7 \%$ of providers). ${ }^{7}$ This discrepancy is in large part due to a paucity of reliable data describing the specific risk factors that would make a woman more likely to develop infectious complications in this setting. In this study, we demonstrate that delivery prior to 32 weeks is associated with a 3.8-fold increased odds of postpartum infection when controlling for receipt of intrapartum antibiotics or postpartum antibiotics. A recent secondary analysis using data from 1999 to 2002, identified elevated body mass index (BMI) and preterm delivery at less than 32 weeks as risk factors for postpartum infection in women following vaginal birth after cesarean section. ${ }^{16}$ Our study, using recent data, demonstrates a similarly elevated risk among women delivering vaginally preterm.

This patient cohort is larger than any other published studies that previously examined the morbidity associated with chorioamnionitis following vaginal delivery. $6,9,10$ Rouse et al found that chorioamnionitis was associated with increased risk of the development of pelvic abscess and septic pelvic thrombophlebitis. ${ }^{8}$ However, this study only included women who underwent cesarean section. Two additional randomized studies attempted to provide evidence for appropriate postpartum management following vaginal delivery. In one study, one dose of postpartum antibiotics was found to be equivalent to 48 or more hours of postpartum antibiotics, but only 109 women were enrolled and there was no study arm that did not receive postpartum antibiotics. ${ }^{9}$ The other study did include a study arm that received no postpartum antibiotics, but only 41 women were enrolled total making it difficult to determine if the study 
Table 4 Labor and delivery details

\begin{tabular}{|c|c|c|c|}
\hline & $\begin{array}{l}\text { With } \\
\text { postpartum } \\
\text { infection } \\
n=23(\%)\end{array}$ & $\begin{array}{l}\text { Without } \\
\text { postpartum } \\
\text { infection } \\
n=323(\%)\end{array}$ & $p$-Value \\
\hline Induction & $9(39.1)$ & $125(38.7)$ & $>0.99$ \\
\hline Median $T_{\max }(\mathrm{IQR})$ & $\begin{array}{l}38.4(38.1 \\
38.7)\end{array}$ & $\begin{array}{l}38.4(38.1, \\
38.9)\end{array}$ & 0.99 \\
\hline $\begin{array}{l}\text { Maternal } \\
\text { tachycardia }\end{array}$ & $13(56.5)$ & $136(42.1)$ & 0.2 \\
\hline Fetal tachycardia & $10(43.5)$ & $165(51.1)$ & 0.52 \\
\hline Fundal tenderness & $3(13)$ & $14(4.3)$ & 0.09 \\
\hline Purulent discharge & 0 & $10(3.1)$ & $>0.99$ \\
\hline $\begin{array}{l}\text { Operative vaginal } \\
\text { delivery }\end{array}$ & $7(30.4)$ & $63(19.5)$ & 0.28 \\
\hline Meconium & $6(26.1)$ & $107(33.1)$ & 0.65 \\
\hline Episiotomy & $3(13)$ & $14(4.3)$ & 0.10 \\
\hline $\begin{array}{l}\text { Third or fourth } \\
\text { deg laceration }\end{array}$ & $4(17.4)$ & $7(2.2)$ & 0.14 \\
\hline $\begin{array}{l}\text { Postpartum } \\
\text { hemorrhage }\end{array}$ & $1(4.3)$ & $29(9)$ & 0.71 \\
\hline $\begin{array}{l}\text { Median EBL at } \\
\text { delivery (IQR) }\end{array}$ & $\begin{array}{l}300 \\
(200,400)\end{array}$ & $\begin{array}{l}300(250 \\
400)\end{array}$ & 0.48 \\
\hline $\begin{array}{l}\text { Manual placenta } \\
\text { extraction }\end{array}$ & $3(13)$ & $16(5)$ & 0.12 \\
\hline \multicolumn{4}{|l|}{ Antibiotics } \\
\hline Intrapartum & $14(60.9)$ & $236(73.1)$ & 0.23 \\
\hline Postpartum & $12(52.2)$ & $99(30.7)$ & 0.03 \\
\hline $\begin{array}{l}\text { Number of doses } \\
\text { of antibiotics } \\
\text { intrapartum (IQR) }\end{array}$ & $2(2,2)$ & $2(2,3)$ & 0.63 \\
\hline $\begin{array}{l}\text { Delivery prior } \\
\text { to } 32 \mathrm{wk}\end{array}$ & $4(17.4)$ & $16(5)$ & 0.04 \\
\hline $\begin{array}{l}\text { Median gestational } \\
\text { age at delivery (IQR) }\end{array}$ & $\begin{array}{l}39.3(37.5 \\
40.4)\end{array}$ & $\begin{array}{l}39.6(38.6, \\
40.4)\end{array}$ & 0.27 \\
\hline
\end{tabular}

Abbreviations: EBL, estimated blood loss; IQR, interquartile range.

Table 5 Adjusted odds of postpartum infectious complications

\begin{tabular}{|l|l|l|}
\hline & aOR & $95 \% \mathrm{Cl}$ \\
\hline Delivery prior to 32 wk & 3.84 & $(1.07-13.7)$ \\
\hline Intrapartum antibiotics & 0.43 & $(0.17-1.10)$ \\
\hline Postpartum antibiotics & 2.25 & $(0.91-5.58)$ \\
\hline
\end{tabular}

Abbreviations: aOR, adjusted odds ratio; $\mathrm{Cl}$, confidence interval.

was adequately powered. ${ }^{10} \mathrm{~A}$ final study managed to enroll 292 women, but this study was not limited to those who delivered vaginally and all women received at least one postpartum dose of antibiotics. ${ }^{12}$

It would be remiss to not comment on the receipt of postpartum antibiotics, which was more common among women with postpartum infections. We believe this is related to clinicians' ability to recognize and treat this subset of high-risk women due to insufficient intrapartum antibiotic therapy or continued or worsening signs of infection in the postpartum period, rather than antibiotic failure.

This study provides an important counterpart to existing literature on the occurrence of postpartum infections following cesarean delivery. While datasets focused on postpartum morbidity from chorioamnionitis after cesarean section have been published, the incidence of these complications after vaginal delivery and the associated risk factors are not well documented. ${ }^{8}$ Although we were only able to identify a cohort of 346 women, this group was similar with respect to many factors that may have affected their risk of complications such as insurance status, STI during pregnancy, BMI, gestational diabetes, and group B Streptococcus colonization.

One of the greatest challenges that we faced in analyzing the data from this study is the difficulty in assessing adequacy of the intrapartum antibiotics regimen. The majority of women, once diagnosed with clinical chorioamnionitis, were treated with ampicillin and gentamicin. However, the decision to initiate treatment and at what time to do so is at the discretion of each provider. Although we did not measure the exact time from diagnosis of chorioamnionitis to delivery, we found that there was no difference in the number of doses of antepartum antibiotics received between women who did versus did not develop a postpartum infection. The same limitation is also present for postpartum antibiotic regimens and length of postpartum treatment. This was not a randomized controlled study; therefore, the women who received postpartum antibiotics did not all receive the same regimen and did not all receive the same number of doses postpartum. Furthermore, although our sample size was large enough to show statistical significance for preterm delivery prior to 32 weeks, we were limited in the number of participants due to the retrospective nature of the study. Additionally, retrospective studies can only comment on associations but not on causality. Of particular interest in a larger cohort or in a prospective study, we would be to investigate whether the differences in rates of third and fourth degree lacerations, manual placenta extraction, episiotomy, and operative delivery became significant as these occurrences were all more common in the group that experienced infectious complications. We were further limited by a small number of outcomes. Thus, in an effort to not overfit the regression model, we were only able to control for a few factors. Though, we selected those who were most significant clinically or statistically. Finally, this study relies upon the clinical diagnosis of chorioamnionitis as determined by the clinician. It is not the current practice in our center to routinely culture placentas or uteri, and thus, we are unable to define any microbiologic differences between the study groups.

In conclusion, in this cohort of women who delivered vaginally in the setting of chorioamnionitis, $6.6 \%$ had a postpartum infection and $9.8 \%$ had a noninfectious postpartum morbidity. This study identified preterm vaginal delivery complicated by chorioamnionitis prior to 32 weeks as one risk factor for postpartum infections, even after controlling for confounders that may warrant consideration of postpartum antibiotics. 
e164 Risk Factors for Postpartum Maternal Infection Following SVD Daifotis et al.

\section{Financial Support}

None.

\section{Meeting Presentation Disclosure}

These data were presented in part as a poster presentation at the American College of Obstetricians and Gynecologists Annual Clinical and Scientific Meeting, May 2-5, 2019, in Nashville, TN.

\section{Conflict of Interest}

None declared.

\section{References}

1 Gibbs RS, Duff P. Progress in pathogenesis and management of clinical intraamniotic infection. Am J Obstet Gynecol 1991;164(5 Pt 1):1317-1326

2 Chapman E, Reveiz L, Illanes E, Bonfill Cosp X. Antibiotic regimens for management of intra-amniotic infection. Cochrane Database Syst Rev 2014;(12):CD010976

3 Tita AT, Andrews WW. Diagnosis and management of clinical chorioamnionitis. Clin Perinatol 2010;37(02):339-354

4 Mark S, Croughan-Minihane M, Kilpatrick S. Chorioamnionitis and uterine function. Obstet Gynecol 2000;95(06):909-912

5 Satin AJ, Maberry MC, Leveno KJ, Sherman ML, Kline DM. Chorioamnionitis: a harbinger of dystocia. Obstet Gynecol 1992;79 (06):913-915

6 Sperling RS, Ramamurthy RS, Gibbs RS. A comparison of intrapartum versus immediate postpartum treatment of intra-amniotic infection. Obstet Gynecol 1987;70(06):861-865

7 Greenberg MB, Anderson BL, Schulkin J, Norton ME, Aziz N. A first look at chorioamnionitis management practice variation among US obstetricians. Infect Dis Obstet Gynecol 2012;2012:628362
8 Rouse DJ, Landon M, Leveno KJ, et al; National Institute of Child Health And Human Development, Maternal-Fetal Medicine Units Network. The Maternal-Fetal Medicine Units cesarean registry: chorioamnionitis at term and its durationrelationship to outcomes. Am J Obstet Gynecol 2004;191(01): 211-216

9 Chapman SJ, Owen J. Randomized trial of single-dose versus multiple-dose cefotetan for the postpartum treatment of intrapartum chorioamnionitis. Am J Obstet Gynecol 1997;177(04): 831-834

10 Berry C, Hansen KA, McCaul JF. Abbreviated antibiotic therapy for clinical chorioamnionitis: a randomized trial. J Matern Fetal Med 1994;3(05):216-218

11 Committee on Obstetric Practice. Committee Opinion No. 712: intrapartum management of intraamniotic infection. Obstet Gynecol 2017;130(02):e95-e101

12 Edwards RK, Duff P. Single additional dose postpartum therapy for women with chorioamnionitis. Obstet Gynecol 2003;102(5 Pt 1):957-961

13 Levy MM, Fink MP, Marshall JC, et al; SCCM/ESICM/ACCP/ATS/SIS. 2001 SCCM/ESICM/ACCP/ATS/SIS International Sepsis Definitions Conference. Crit Care Med 2003;31(04):1250-1256

14 Higgins RD, Saade G, Polin RA, et al; Chorioamnionitis Workshop Participants. Evaluation and management of women and newborns with a maternal diagnosis of chorioamnionitis: summary of a workshop. Obstet Gynecol 2016;127(03): 426-436

15 Venkatesh KK, Glover AV, Vladutiu CJ, Stamilio DM. Association of chorioamnionitis and its duration with adverse maternal outcomes by mode of delivery: a cohort study. BJOG 2019;126(06): 719-727

16 Denoble AE, Heine RP, Dotters-Katz SK. Chorioamnionitis and infectious complications after vaginal delivery. Am J Perinatol 2018;219(06):648 